\title{
Propionate induces the bovine cytosolic phosphoenolpyruvate carboxykinase promoter activity
}

\author{
Qian Zhang, Stephanie L. Koser, and Shawn S. Donkin ${ }^{1}$ \\ Department of Animal Sciences, Purdue University, West Lafayette, IN 47907
}

\section{ABSTRACT}

Cytosolic phosphoenolpyruvate carboxykinase $(P C K 1)$ is a critical enzyme within the metabolic networks for gluconeogenesis, hepatic energy metabolism, and tricarboxylic acid cycle function, and is controlled by several transcription factors including hepatic nuclear factor $4 \alpha(\mathrm{HNF} 4 \alpha)$. The primary objective of the present study was to determine whether propionate regulates bovine $P C K 1$ transcription. The second objective was to determine the action of cyclic AMP (cAMP), glucocorticoids, and insulin, hormonal cues known to modulate glucose metabolism, on bovine $P C K 1$ transcriptional activity. The proximal promoter of the bovine PCK1 gene was ligated to a Firefly luciferase reporter and transfected into H4IIE hepatoma cells. Cells were exposed to treatments for $23 \mathrm{~h}$ and luciferase activity was determined in cell lysates. Activity of the PCK1 promoter was linearly induced by propionate, and maximally increased 7 -fold with $2.5 \mathrm{mM}$ propionate, which was not muted by $100 \mathrm{n} M$ insulin. Activity of the PCK1 promoter was increased 1-fold by either $1.0 \mathrm{~m} M$ cAMP or $5.0 \mu M$ dexamethasone, and 2.2-fold by their combination. Induction by cAMP and dexamethasone was repressed $50 \%$ by $100 \mathrm{n} M$ insulin. Propionate, cAMP, and dexamethasone acted synergistically to induce the $P C K 1$ promoter activity. Propionate-responsive regions, identified by $5^{\prime}$ deletion analysis, were located between $-1,238$ and $-409 \mathrm{bp}$ and between -85 and +221 bp. Deletions of the core sequences of the 2 putative HNF $4 \alpha$ sites decreased the responsiveness to propionate by approximately $40 \%$. These data indicate that propionate regulates its own metabolism through transcriptional stimulation of the bovine $P C K 1$ gene. This induction is mediated, in part, by the 2 putative $\mathrm{HNF} 4 \alpha$ binding sites in the bovine PCK1 promoter.

Key words: hormone, short-chain fatty acid, PCK1, promoter

Received February 27, 2016.

Accepted April 30, 2016.

${ }^{1}$ Corresponding author: sdonkin@purdue.edu

\section{INTRODUCTION}

Phosphoenolpyruvate carboxykinase (PCK; EC 4.1.1.32), a key enzyme of gluconeogenesis, tricarboxylic acid (TCA) cycle function, and several metabolic networks that affect energy metabolism in the liver and kidney, catalyzes the irreversible formation of phosphoenolpyruvate from oxaloacetate (Rognstad, 1979; She et al., 2000; Burgess et al., 2007). It is well documented in nonruminant species that the gene for the cytosolic form of PCK (PCK1) is actively regulated by hormones and nutrients at the transcriptional level, most notably through induction by glucagon and glucocorticoids, effects that are repressed by insulin action (Hanson and Reshef, 1997). Accordingly, expression of PCK1 is induced by starvation and reduced during feeding (Hanson and Reshef, 1997). However, in ruminants, the expression of $P C K 1$ is not altered during feed restriction (Velez and Donkin, 2005), but is induced in response to increased feed intake (Greenfield et al., 2000) and monensin feeding (Karcher et al., 2007), conditions that are linked to increased ruminal propionate production. Expression of PCK1 mRNA is increased in neonatal calves and at least maintained with postruminal propionate infusions in lactating dairy cows despite elevated insulin concentrations (Zhang et al., 2015), a hormone that potently and rapidly represses PCK1 mRNA expression (Granner et al., 1983; Chakravarty and Hanson, 2007).

Studies using primary rat hepatocytes and H4IIE rat hepatoma cells indicate that short-chain fatty acids (SCFA), including propionate and butyrate, modulate expression of both PCK1 mRNA and G6PC mRNA (Massillon et al., 2003). Binding of hepatic nuclear factor $4 \alpha(\mathbf{H N F} 4 \boldsymbol{\alpha})$ to mouse $G 6 P C$ promoter is required for stimulation of transcription by propionate and butyrate (Massillon et al., 2003). Hepatic nuclear factor $4 \alpha$ is a member of the nuclear receptor superfamily abundantly expressed in the liver and required for liverspecific gene expression in response to hormones and nutrients (Sladek et al., 1990; Babeu and Boudreau, 2014). Upon binding to its recognition sites in a gene promoter, HNF4a is able to recruit coactivators of transcription factors, such as peroxisome proliferator- 
activated receptor $\gamma$ coactivator-1 $\alpha$, to stimulate transcriptional activity (Gonzalez, 2008). The critical role of $\mathrm{HNF} 4 \alpha$ in activating transcription of the PCK1 and $G 6 P C$ gene has also been confirmed using hepatocytes from mice lacking hepatic HNF4 $\alpha$ (Rhee et al., 2003).

These observations led us to question if the induction of PCK1 mRNA expression by propionate in liver of dairy cattle might be due to direct activation of the bovine PCK1 promoter. We were likewise interested in determining the relationship between propionate, glucagon, glucocorticoids, and insulin on bovine PCK1 gene transcription. In addition, the bovine PCK1 promoter was analyzed to reveal putative transcription factor binding sites and the functionality of the putative $\mathrm{HNF} 4 \alpha$ binding sites in mediating responses to propionate and butyrate were tested. Here, we show that propionate has an inductive effect on the transcriptional activity of the bovine $P C K 1$ promoter, which is dominant to the repressive effect of insulin and synergistic to the inductive effect of the combination of cyclic AMP (cAMP) and dexamethasone. We also demonstrate that 2 putative $H N F 4 \alpha$-binding sites within the bovine $P C K 1$ promoter are responsible, in part, for propionate-induced $P C K 1$ transcription.

\section{MATERIALS AND METHODS}

\section{Promoter-Luciferase Reporter Constructs}

The bovine PCK1 proximal promoter sequence was obtained from National Center for Biotechnology Information database (https://www.ncbi.nlm.nih.gov/). The DNA sequence containing the proximal promoter region from $-1,238$ through +221 bp relative to the transcription start site (TSS) of the bovine PCK1 gene (NCBI Gene ID: 282855) was linked to a Firefly luciferase reporter. The promoter region corresponds to bases 59,151,952 through 59,150,494 of the bovine chromosome 13 . To determine the propionate-responsive elements within the bovine $P C K 1$ promoter, $5^{\prime}$ nested deletions of the proximal promoter region were individually linked to the Firefly luciferase reporter. The target promoter sequences were amplified from bovine genomic DNA by PCR using the primers presented in Table 1. The amplified PCR products were purified using agarose gel electrophoresis and the QIAquick Gel Extraction Kit (Qiagen, Valencia, CA) and each was ligated into the pDrive cloning vector (Qiagen), which was used to transform Qiagen EZ Competent Cells (Qiagen). Positive clones were grown individually overnight for plasmid DNA isolation using the Wizard Plus SV Miniprep kit (Promega, Madison, WI). The cloned sequences were then excised from pDrive and ligated separately into the pGL3-Basic vector (Promega). Each $P C K 1$ promoter-luciferase plasmid was used to transform competent JM109 Escherichia coli, and positive clones were grown individually overnight for plasmid DNA isolation using the Wizard Plus SV Miniprep kit (Promega). Insert sequence and orientation of the promoter regions were verified by sequencing at the DNA Sequencing Low Throughput Laboratory of Purdue Genomics Core Facility (Purdue University, West Lafayette, IN) using the ABI 3700 sequencer (Amersham Biosciences, Piscataway, NJ).

\section{In Silico Promoter Sequence Analysis}

The bovine PCK1 proximal promoter sequence $(-1,238 /+221)$ was analyzed using the TRANSFAC transcription factor analysis tool (Biobase, Beverly, MA). The search parameters were limited to liver-specific factors, high-quality matrices, and set to minimize false positives.

\section{Site-Directed Mutagenesis}

The essentiality of the putative HNF $4 \alpha$ binding sites within the bovine $P C K 1$ gene located at +68 through

Table 1. Primer sequences used to amplify the promoter regions of the bovine PCK1 gene and for the site-directed mutagenesis

\begin{tabular}{|c|c|}
\hline Promoter construct & Primer sequence $\left(5^{\prime}-3^{\prime}\right)$ \\
\hline$P C K 1$ promoter $(-815 /+221)$ & Forward: AATCCACAAGGCAGGTGTGACTGA \\
\hline$P C K 1$ promoter $(-409 /+221)$ & Forward: ACCACTGCTCTATTCTGGCAACCA \\
\hline$P C K 1$ promoter $(-85 /+221)$ & Forward: AGTCGAGCCTCTCTGGGTGTG \\
\hline All promoter regions of $P C K 1$ & Reverse: AGAGTTGAGGGTGTCCATGGTTGT \\
\hline Mutant $\operatorname{HNF} 4 \alpha_{\left(+68_{-}+72\right)}$ & Forward: AAGGGACCCTTTGGCTGACCTGATCGTCCA \\
\hline Mutant $\operatorname{HNF} 4 \alpha_{\left(-1,078_{-}-1,074\right)}$ & Reverse: CCTCTTGTAAGGGACCCCTTCCTGGAACCT \\
\hline \multirow[t]{2}{*}{ Double mutant $\mathrm{HNF} 4 \alpha_{\left(+68_{-}+72\right)}^{-} / \mathrm{HNF} 4 \alpha_{\left(-1,078_{-}-1,074\right)}{ }^{-}$} & Forward: AAGGGACCCTTTGGCTGACCTGATCGTCCA \\
\hline & Reverse: TGGACGATCAGGTCAGCCAAAGGGTCCCTT \\
\hline
\end{tabular}


$+72 \mathrm{bp}$ and $-1,078$ through $-1,074$ bp relative to TSS for the bovine PCK1 promoter responsiveness to the tested treatments were determined using site-directed mutagenesis. Mutations of the putative HNF $4 \alpha$ binding sites were generated using the GENEART Site-Directed Mutagenesis System kit (Life Technologies, Grand Island, NY) following the manufacturer protocols. The primers used for the mutagenesis are shown in Table 1. Three mutant promoters were tested relative to the wild-type promoter $\left[P C K 1_{(\mathrm{WT})}\right]$ in these experiments. The mutant $\mathrm{HNF} 4 \alpha_{\left(+68_{+}+72\right)}$ was created by deleting the core sequence of the putative $\mathrm{HNF} 4 \alpha$ binding site at +68 through +72 bp (5'-CTCTG-3') using the $P C K 1_{(\text {WT })}$ as template. The mutant $\mathrm{HNF} 4 \alpha_{(-1,078}{ }_{-1,074)}{ }^{-}$was created by deleting the core sequence of the putative $\mathrm{HNF} 4 \alpha$ site at $-1,078$ through $-1,074$ bp (5'-CAAAG-3') using the $P C K 1_{(\mathrm{WT})}$ as template. The double mutant $\mathrm{HNF} 4 \alpha_{\left(+68_{+}+72\right)} / \mathrm{HNF} 4 \alpha_{\left(-1,078_{-}-1,074\right)}{ }^{-}$was created by deleting the core sequences of the putative $\mathrm{HNF} 4 \alpha$ site at +68 through $+72 \mathrm{bp}\left(5^{\prime}\right.$-CTCTG-3') and at $-1,078$ through $-1,074$ bp (5'-CAAAG-3') using the mutant $\mathrm{HNF}_{4} \alpha_{\left(-1,078_{-}-1,074\right)}{ }^{-}$as template. All promoter-luciferase reporter plasmids were sequenced at the DNA Sequencing Low Throughput Laboratory of Purdue Genomics Core Facility to verify the target mutations.

\section{Cell Culture}

Rat hepatoma H4IIE cells were obtained from the American Type Culture Collection (Manassas, VA) and grown in Dulbecco's Modified Eagle's Medium (DMEM; Sigma-Aldrich, St. Louis, MO) containing $4.5 \mathrm{~m} M$ glucose supplemented with $10 \%$ fetal bovine serum (Sigma-Aldrich) and antibiotics (10 mg/L piperacillin and $10 \mathrm{mg} / \mathrm{L}$ ciprofloxacin; Sigma-Aldrich) at $37^{\circ} \mathrm{C}, 95 \%$ relative humidity, and $5 \% \mathrm{CO}_{2}$. Cells were seeded in 24-well Corning Costar tissue culture plates (Corning Inc., Tewksbury, MA) at a target density of 75,000 cells per $\mathrm{cm}^{2}$ and grown for $24 \mathrm{~h}$ to achieve approximately $80 \%$ confluence.

\section{Test of Promoter Function}

Transient transfections in H4IIE cells were performed using Lipofectamine 2000 (Invitrogen Inc., Waltham, MA) according to the manufacturer's instruction. For transfection, cell culture medium was DMEM supplemented with 1\% BSA (Merck Millipore, Billerica, MA) but without antibiotics. A volume of $100 \mu \mathrm{L}$ of the lipofectamine-plasmid mixture containing $98 \mu \mathrm{L}$ of Opti-MEM I Reduced Serum Medium (Life Technologies Inc.), $2 \mu \mathrm{L}$ of lipofectamine, $0.8 \mu \mathrm{g}$ of each tested plasmid, and $0.008 \mu \mathrm{g}$ of a Renilla pRL-CMV luciferase plasmid (Promega) was added to each well. Cotransfection of Renilla pRL-CMV luciferase plasmid was used to normalize transfection efficiency.

Five hours after transfection, medium was removed by aspiration and replaced with the treatment additions to DMEM containing 1\% BSA and antibiotics $(10 \mathrm{mg} / \mathrm{L}$ of piperacillin and $10 \mathrm{mg} / \mathrm{L}$ of ciprofloxacin). Cells were exposed to treatments for $23 \mathrm{~h}$. Basal promoter activity and responsiveness to propionate and hormones were tested in a series of complementary experiments. Briefly, DMEM supplemented with $1 \%$ BSA and antibiotics $(10 \mathrm{mg} / \mathrm{L}$ of piperacillin and $10 \mathrm{mg} / \mathrm{L}$ of ciprofloxacin) was used to determine the basal promoter activity. Responsiveness of the PCK1 promoter was determined in the presence of $0,0.25,0.5$, 1.0 , or $2.5 \mathrm{mM}$ propionate. The effects of SCFA and glycerol on the PCK1 promoter were tested in DMEM containing 1\% BSA and antibiotics and either $2.5 \mathrm{mM}$ acetate, $2.5 \mathrm{~m} M$ propionate, $2.5 \mathrm{~m} M$ butyrate, or 2.5 $\mathrm{m} M$ glycerol. Medium without SCFA or glycerol served as the control. The relationship between propionate and hormone additions was determined in the presence of either $2.5 \mathrm{~m} M$ propionate, $100 \mathrm{n} M$ insulin, $1.0 \mathrm{~m} M$ 8-Br-cAMP, 5.0 $\mu M$ dexamethasone, or their combinations. To determine the location of DNA regulatory elements required for propionate action, $5^{\prime}$ nested deletions of $P C K 1$ proximal promoter ligated to luciferase reporter were individually transfected into H4IIE cells and exposed to either 0 or $2.5 \mathrm{~m} M$ propionate. The role of $\mathrm{HNF} 4 \alpha$ in $P C K 1$ promoter response to propionate and butyrate was determined using the following mutants: $\mathrm{HNF} 4 \alpha_{\left(+68_{-}+72\right)}{ }^{-}, \mathrm{HNF} 4 \alpha_{\left(-1,078_{-}-1,074\right)}{ }^{-}$, and the double mutant $\mathrm{HNF} 4 \alpha_{\left(+68_{-}+72\right)}{ }^{-} / \mathrm{HNF} 4 \alpha_{\left(-1,078_{-}-1,074\right)}{ }^{-}$. Each mutant plasmid was individually transfected into H4IIE cells, and cells were exposed to either no addition, $2.5 \mathrm{~m} M$ propionate, or $2.5 \mathrm{~m} M$ butyrate.

\section{Luciferase Activity}

Following $23 \mathrm{~h}$ of exposure to treatments, medium was removed by aspiration and cells were washed with $250 \mu \mathrm{L}$ of ice-cold $1 \times$ PBS and harvested in $80 \mu \mathrm{L}$ of $1 \times$ passive lysis buffer (Promega). Firefly luciferase and Renilla luciferase were quantified with the DualLuciferase Reporter Assay system and the Stop \& Glo Reagent kit according to the manufacturer's instruction (Promega). Fluorescence was determined with Magellan 5.0 software (Tecan, Research Triangle Park, NC) using a Tecan GENios Pro spectrofluorometer. Promoter activity was expressed as the ratio of Firefly luciferase to Renilla luciferase, and treatment effect was expressed as the fold change relative to the no-addition controls. 


\section{Statistical Analysis}

All experiments were conducted in at least 3 separate cell preparations using 3 replicates per treatment. Data were analyzed for normality using the Univariate procedure of SAS 9.2 (SAS Institute Inc., Cary, $\mathrm{NC}$ ), and any heteroscedastic data were adjusted to achieve normality using a natural logarithm transformation. Analyses of variance were performed using the Proc Mixed procedure of SAS 9.2. Data from multiple promoter luciferase reporter constructs were evaluated using a model that accounted for the fixed effects of construct and cell preparation. Data from the full length $P C K 1$ promoter $(-1,238 /+221)$ were evaluated using a model that accounted for the fixed effects of treatment and cell preparation. Contrast statement was included to test linearity for the dose-response experiment. A linear regression trend line with coefficient of determination values was generated using an Excel spreadsheet (Microsoft Corp., Redmond, WA). For the data that were not adjusted using logarithm transformation, least squares means and standard errors were reported. For the data that were adjusted using logarithm transformation, least squares means and $95 \%$ confidence intervals were reported using the original scale. Tukey-Kramer studentized adjustments were used to separate treatment means when main effects were significant. Means were considered different when $P<0.05$.

\section{RESULTS}

\section{Basal Promoter Activity of the Bovine PCK1 Gene}

The pGL3-luciferase family of constructs served as controls in this experiment. The promoterless parent vector, pGL3-Basic, served as a negative control, and pGL3- SV40 Promoter containing a SV40 promoter element served as a positive control. Activity of the positive control pGL3- SV40 Promoter was significantly greater than the negative control pGL3-Basic $(P<0.05 ;$ Figure 1$)$. The ability of the bovine PCK1 promoter $(-1,238 /+221)$ to drive luciferase expression was greater $(P<0.05)$ than the pGL3-Basic negative control and similar to the pGL3- SV40 Promoter positive control (Figure 1). Compared with the fulllength $P C K 1$ promoter $(-1,238 /+221)$, the ability to drive luciferase expression was increased $(P<0.05)$ for the PCK1 promoter $(-409 /+221)$ and promoter $(-251 /+221 ;$ Figure 1$)$. The activity of the minimum $P C K 1$ promoter $(-85 /+221)$ was still greater than the pGL3-Basic negative control $(P<0.05$; Figure 1$)$.

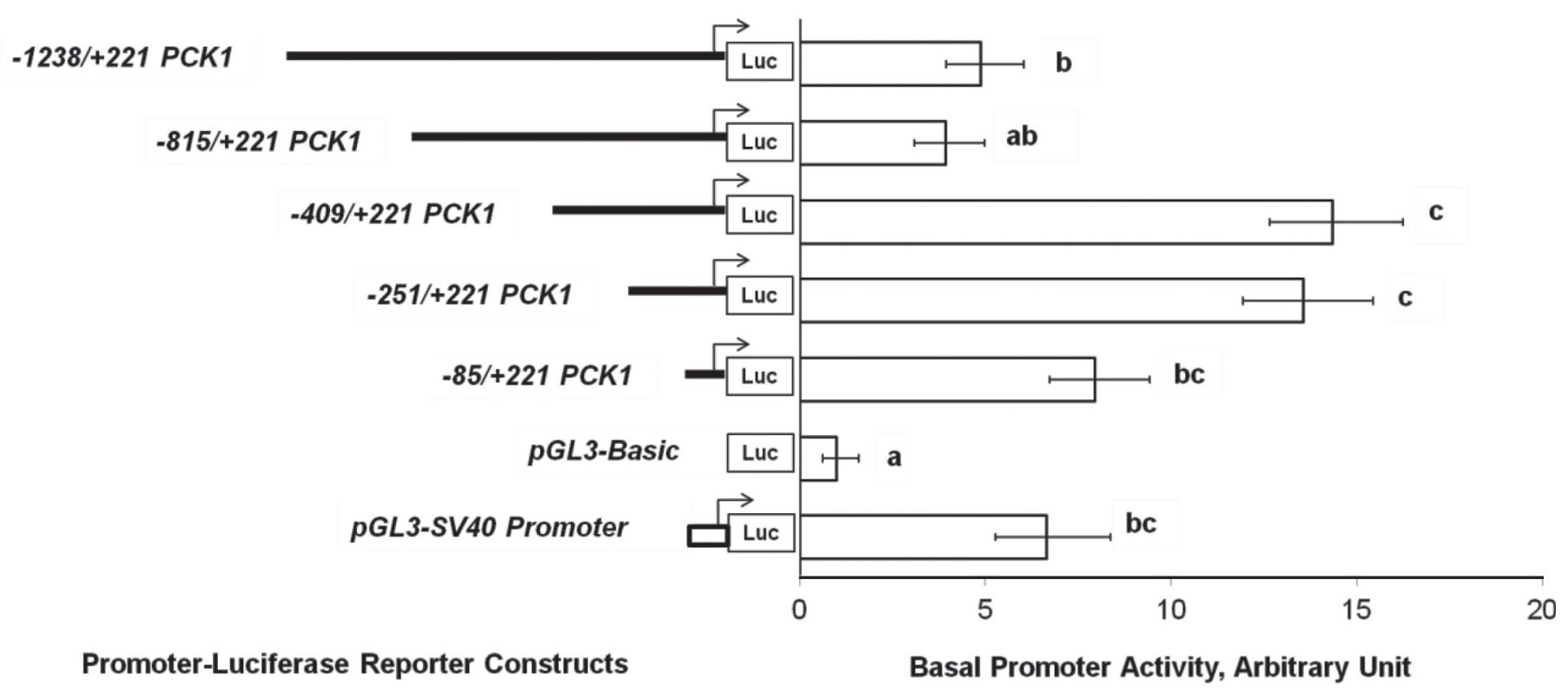

Figure 1. Basal activity of the PCK1 promoter reporter constructs in rat hepatoma H4IIE cells. Cells were transfected with each individual promoter reporter construct and incubated in Dulbecco's Modified Eagle's Medium (Sigma-Aldrich, St. Louis, MO) containing 1\% bovine serum albumin (Merck Millipore, Billerica, MA) and antibiotics for $23 \mathrm{~h}$. The pGL3-Basic (Promega, Madison, WI) was promoterless and used as a negative control, and the pGL3-SV40 Promoter served as positive control. Values are LSM and 95\% CI, $\mathrm{n}=3$. Labeled means without a common letter $(\mathrm{a}-\mathrm{c})$ differ at $P<0.05$. 


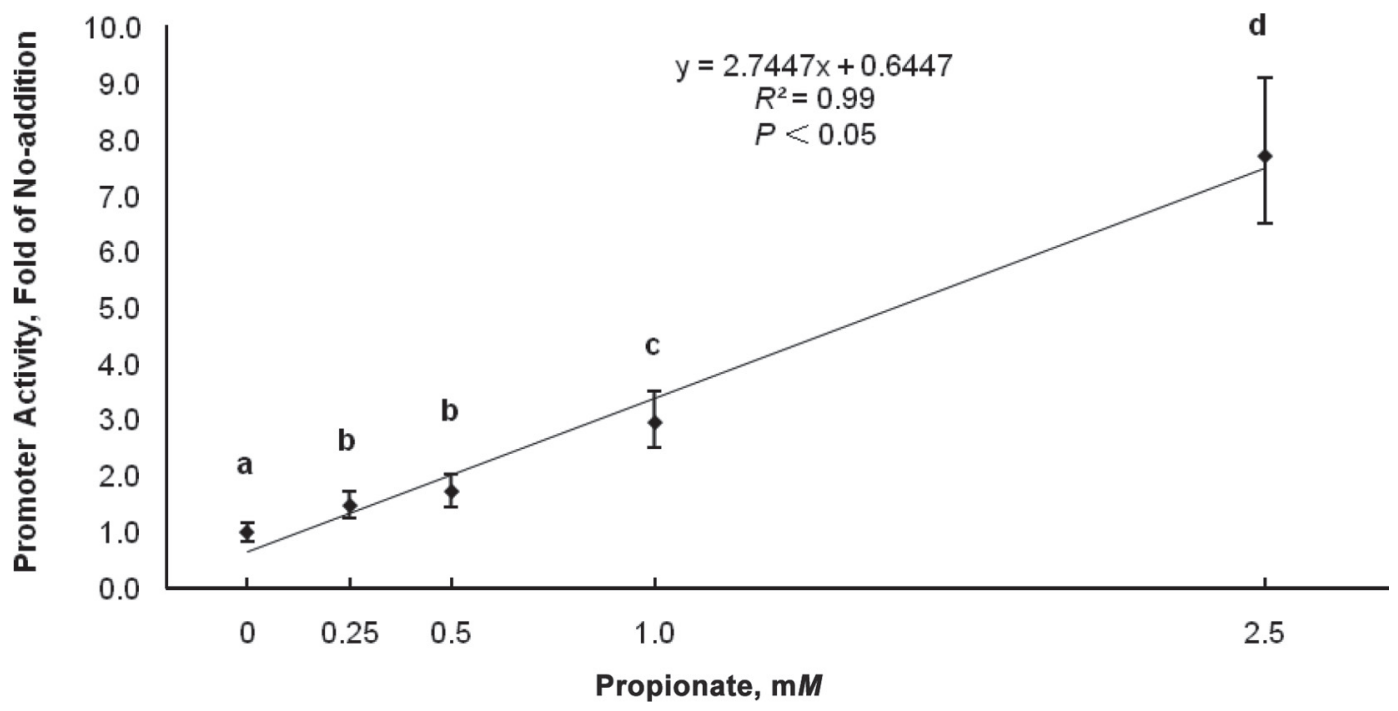

Figure 2. Effect of propionate on the activity of the bovine PCK1 promoter in rat hepatoma H4IIE cells. Cell were transfected with the PCK1 promoter $(-1,238 /+221)$ reporter construct and exposed to $0,0.25,0.5,1.0$, or $2.5 \mathrm{~m} M$ of propionate for $23 \mathrm{~h}$. Treatment effects are expressed as the fold change relative to the no-addition control. Values are LSM and $95 \% \mathrm{CI}, \mathrm{n}=3$. Labeled means without a common letter (a-d) differ at $P<0.05$. Induction of the $P C K 1$ promoter activity shows a linear regression with increasing propionate concentrations.

\section{Dose-Dependent Induction of Bovine PCK1 Transcription by Propionate}

Propionate at $0.25,0.5,1.0$, and $2.5 \mathrm{~m} M$ linearly increased $(P<0.05)$ the activity of the bovine PCK1 promoter $(-1,238 /+221$; Figure 2$)$. Compared with $0 \mathrm{~m} M$ propionate, $0.25 \mathrm{~m} M$ propionate induced $(P<$ $0.05)$ the $P C K 1$ promoter activity 0.5 -fold, and $2.5 \mathrm{mM}$ propionate increased $(P<0.05)$ the promoter activity approximately 7 -fold (Figure 2 ).

\section{Responsiveness of Bovine PCK1 Transcription to SCFA and Glycerol}

Activity of the bovine $P C K 1$ promoter $(-1,238 /+221)$ was induced $(P<0.05)$ by $2.5 \mathrm{mM}$ propionate and 2.5 $\mathrm{m} M$ butyrate, but not by $2.5 \mathrm{~m} M$ acetate $(P \geq 0.05$; Figure 3). The induction by butyrate was greater $(P$ $<0.05$ ) than propionate (Figure 3). Glycerol, another gluconeogenic substrate, did not affect $(P \geq 0.05)$ the $P C K 1$ promoter activity, indicating a lack of general effect of gluconeogenic precursors on $P C K 1$ transcription (Figure 3).

\section{Responsiveness of Bovine PCK1 Transcription to Propionate and Hormonal Cues}

Dexamethasone and cAMP, when present alone, induced $(P<0.05)$ the bovine $P C K 1$ promoter
$(-1,238 /+221)$ by approximately 1 -fold compared with the no-addition control (Figure 4). The combination of cAMP and dexamethasone increased $(P<$ $0.05)$ the $P C K 1$ promoter activity by 2.2 -fold, which was repressed $50 \%$ by insulin (Figure 4). Propionate alone induced $(P<0.05)$ the promoter activity by approximately 7 -fold (Figure 4 ). When propionate was combined with cAMP or dexamethasone, the inductive effects were magnified $(P<0.05) 11$ - and 9 -fold, respectively, and the combination of propionate, cAMP, and dexamethasone synergistically increased $(P<0.05)$ the promoter activity about 23 -fold, which was greater $(P$ $<0.05)$ than the induction by propionate alone (Figure $4)$. In presence of propionate, insulin was without effect $(P \geq 0.05)$ on the bovine $P C K 1$ promoter activity (Figure 4$)$.

\section{Propionate-Responsive Regions Within the Bovine PCK1 Promoter}

Compared with the PCK1 promoter $(-1,238 /+221)$, deletion from $-1,238$ to $-409 \mathrm{bp}$ resulted in increased basal promoter activity but caused a significant loss of propionate inducibility $(P<0.05$; Figure 5$)$. Further deletion from -409 to -85 bp did not alter the responsiveness to propionate (Figure 5). The minimum promoter construct $(-85 /+221)$ was sufficient to mediate responsiveness to propionate compared with the negative control pGL3-Basic $(P<0.05$; Figure 5$)$. Thus, the 2 regions from $-1,238$ to $-409 \mathrm{bp}$ and from -85 


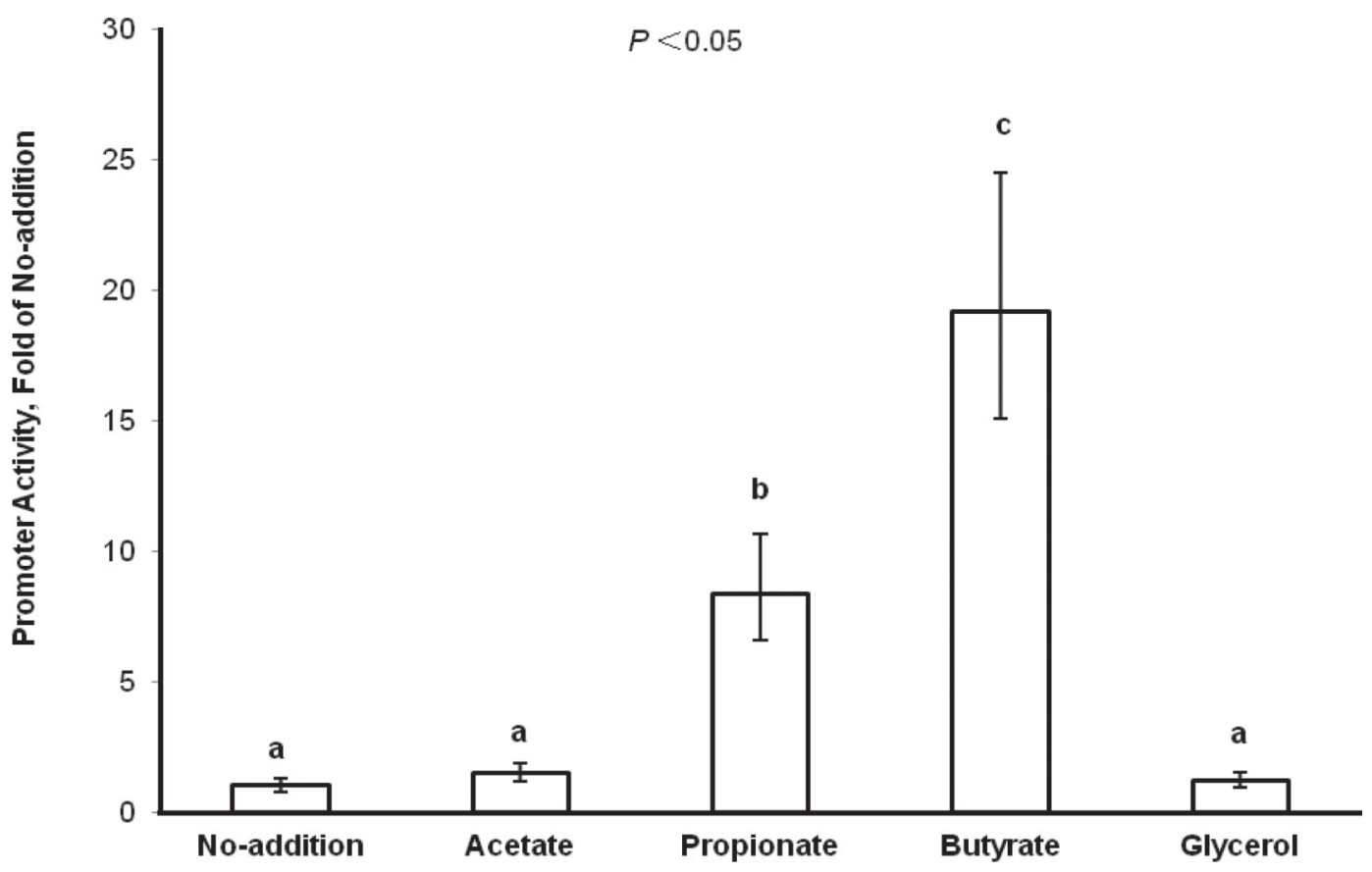

Figure 3. Effects of short-chain fatty acids and glycerol on the activity of the bovine PCK1 promoter in rat hepatoma H4IIE cells. Cell were transfected with the $P C K 1$ promoter $(-1,238 /+221)$ reporter construct and exposed to 0 or $2.5 \mathrm{~m} M$ acetate, $2.5 \mathrm{~m} M$ propionate, $2.5 \mathrm{~m} M$ butyrate, or $2.5 \mathrm{mM}$ glycerol for $23 \mathrm{~h}$. Treatment effects are expressed as the fold change relative to the no-addition control. Values are LSM and $95 \% \mathrm{CI}, \mathrm{n}=3$. Labeled means without a common letter (a-c) differ at $P<0.05$.

to +221 bp relative to TSS accounted for the robust induction of the bovine PCK1 promoter by propionate.

\section{Role of the HNF4a Binding Sites in Propionate- Induced Bovine PCK1 Transcription}

In silico analysis of the bovine PCK1 promoter sequence using TRANSFAC revealed 2 putative $\mathrm{HNF} 4 \alpha$ binding sites at +68 to +72 and $-1,078$ to $-1,074$ bp relative to TSS, respectively (Figure 6). The role of HNF4 $\alpha$ binding sites in mediating propionate and butyrate regulation of bovine $P C K 1$ transcription was examined by deleting the core sequences of $\mathrm{HNF} 4 \alpha$ binding site at +68 to +72 bp [mutant $\left.\mathrm{HNF} 4 \alpha_{\left(+68_{-}+72\right)}{ }^{-}\right]$, at $-1,078$ to $-1,074 \mathrm{bp}$ [mutant $\mathrm{HNF} 4 \alpha_{\left(-1,078_{-}-1,074\right)}{ }^{-}$, or both sites [double mutant $\mathrm{HNF} 4 \alpha_{(+68+72)}$ / $\left.\mathrm{HNF} 4 \alpha_{\left(-1,078_{-}-1,074\right)}{ }^{-}\right]$. Compared with the $P C K 1_{(\mathrm{WT})}$, the mutant $\mathrm{HNF} 4 \alpha_{\left(+68_{-}+72\right)}{ }^{-}$, mutant $\mathrm{HNF} 4 \alpha_{\left(-1,078_{-}-1,074\right)}{ }^{-}$, and double mutant $\mathrm{HNF} 4 \alpha_{\left(+68_{-}+72\right)} / \mathrm{HNF} 4 \alpha_{\left(-1,078_{-}-1,074\right)}$ had increased basal promoter activity, but responsiveness to propionate or butyrate was depressed by about 40\% $(P<0.05 ;$ Figure 7$)$. The basal activity and responsiveness to propionate or butyrate were not different among the 3 mutants. These results indicate the putative $\mathrm{HNF} 4 \alpha$ binding sites are responsible, at least in part, for propionate- and butyrate-mediated induction of bovine $P C K 1$ transcription.

\section{DISCUSSION}

Feeding strategies that increase ruminal propionate production are often used to meet increased glucose demand and reduce the effect of fatty liver and ketosis during early lactation in dairy cows (Baird, 1982; Duffield et al., 1998; Aschenbach et al., 2010). The gluconeogenic effect of propionate appears to be mediated by elevated expression of PCK1 mRNA (Zhang et al., 2015). Induction of $P C K 1 \mathrm{mRNA}$ expression in primary rat hepatocytes and H4IIE cells in response to propionate is due to transcriptional activation (Massillon et al., 2003). Available data indicate that transcription of $P C K 1$ in liver requires an important transcription factor HNF4a (Puigserver, 2005; Gonzalez, 2008). In this study, we demonstrated that propionate, a major gluconeogenic precursor in ruminants, directly regulates bovine PCK1 transcription.

The increase in transcription of bovine PCK1 in response to propionate and butyrate appears to be a specific effect of these SCFA, as acetate was without effect. Likewise, the effects on PCK1 do not appear to be mediated by the availability of gluconeogenic precursors, as glycerol was also without effect. Short-chain fatty acids have been recently identified as ligands for G-protein-coupled receptors, GPR41 and GPR43, also known as free fatty acid receptor (FFAR) 3 and 
FFAR2, respectively (Brown et al., 2003; Layden et al., 2013). These 2 receptor types show ubiquitous expression throughout the human body (Tang et al., 2012) and bovine tissues (Wang et al., 2009; Yonezawa et al., 2009). Acetate and butyrate preferentially bind to FFAR2 and FFAR3, respectively, whereas propionate binds to both receptors. The receptor preferences may have provided some possible explanations for the different responsiveness of bovine $P C K 1$ transcription to SCFA.

Two propionate-responsive regions were identified by $5^{\prime}$ deletion analysis, and promoter analysis revealed 2 putative STAT3 binding sites as well as 2 putative HNF $4 \alpha$ binding sites within these 2 regions (Figure 6). In the present study, we did not test the functionality of STAT3 in mediating responses of bovine PCK1 to propionate and butyrate. It has been reported that STAT3 mediates negative regulation of transcription of gluconeogenic genes, including $P C K 1$ and $G 6 P C$ in mouse liver and HepG2 cells (Ramadoss et al., 2009), which makes it less likely to be involved in the positive regulation of bovine $P C K 1$ transcription by propionate and butyrate. The 2 putative HNF $4 \alpha$ binding sites are involved but not completely responsible for the induction, as deletions of the core sequences of these 2 sites decreased the responsiveness to propionate by approximately $40 \%$. It has been reported that $\mathrm{HNF} 4 \alpha$ plays an important role in regulation of $P C K 1$ and $G 6 P C$ gene expression by both hormonal and nutritional cues (Gonzalez, 2008). Binding sites of HNF4 $\alpha$ have been identified within the promoter of the rat PCK1 and G6PC (Hanson and Reshef, 1997; Massillon et al., 2003; Chakravarty et al., 2005). The induction of mouse $G 6 P C$ transcription by propionate and butyrate requires binding of $\mathrm{HNF} 4 \alpha$ to the $G 6 P C$ promoter (Massillon et al., 2003). Future studies are needed to confirm the binding of HNF4 $\alpha$ to these sites as well as other cis-elements within the bovine $P C K 1$ promoter to mediate the full responsiveness to SCFA.

Although PCK1 is a critical enzyme for gluconeogenesis, it also plays an important cataplerotic role in oxaloacetate (OAA) metabolism. Sufficient OAA in

\section{$P<0.05$}

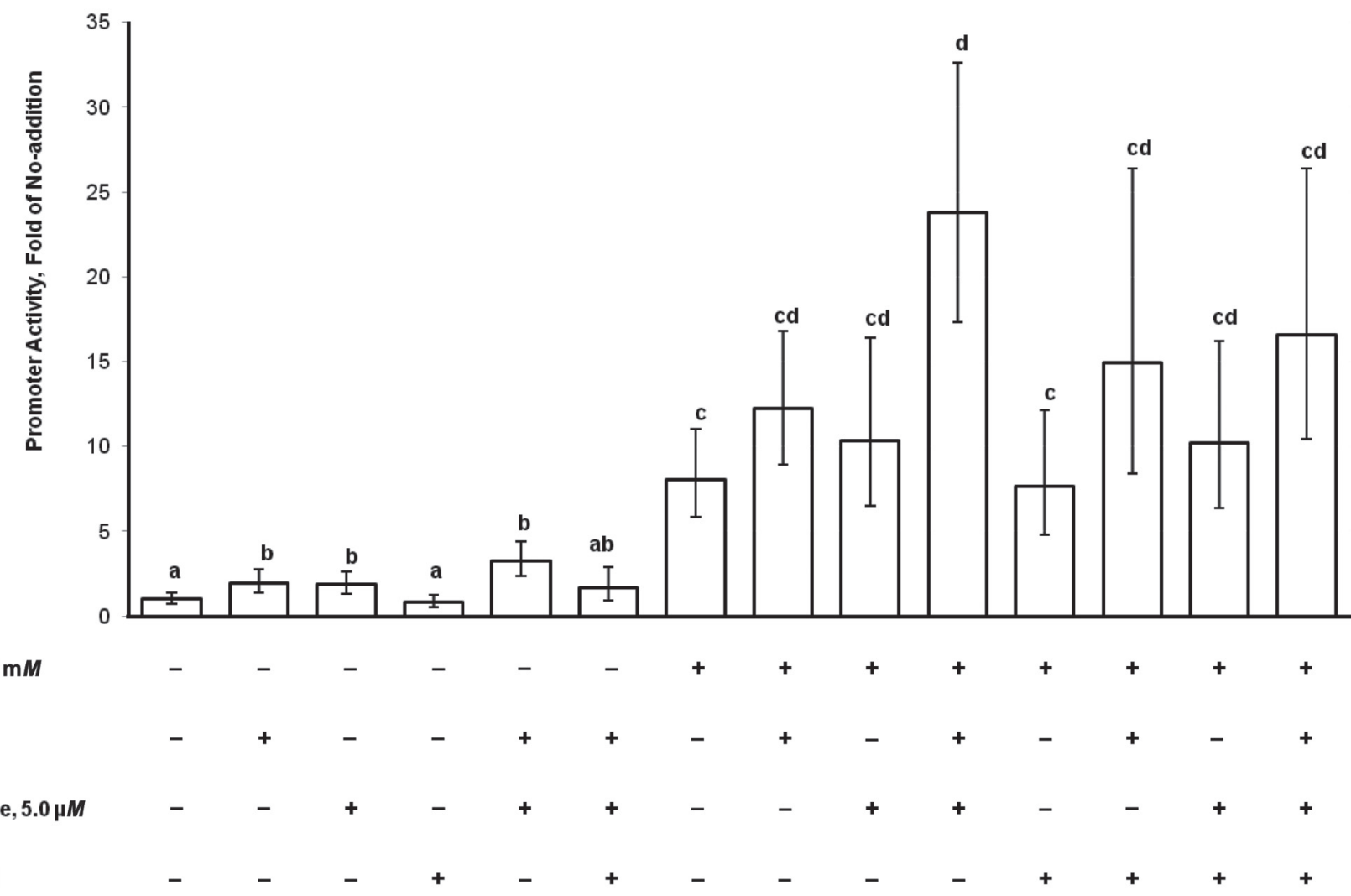

Figure 4. Effects of propionate and hormonal cues on the activity of the bovine PCK1 promoter in rat hepatoma H4IIE cells. Cell were transfected with the $P C K 1$ promoter $(-1,238 /+221)$ reporter construct and exposed to $2.5 \mathrm{~m} M$ propionate, $100 \mathrm{n} M$ insulin, $1.0 \mathrm{~m} M$ cyclic AMP (cAMP), $5.0 \mu M$ dexamethasone, or the combinations indicated for $23 \mathrm{~h}$. Treatment effects are expressed as the fold change relative to the noaddition control. Values are LSM and $95 \% \mathrm{CI}, \mathrm{n}=3$. Labeled means without a common letter (a-d) differ at $P<0.05$. 


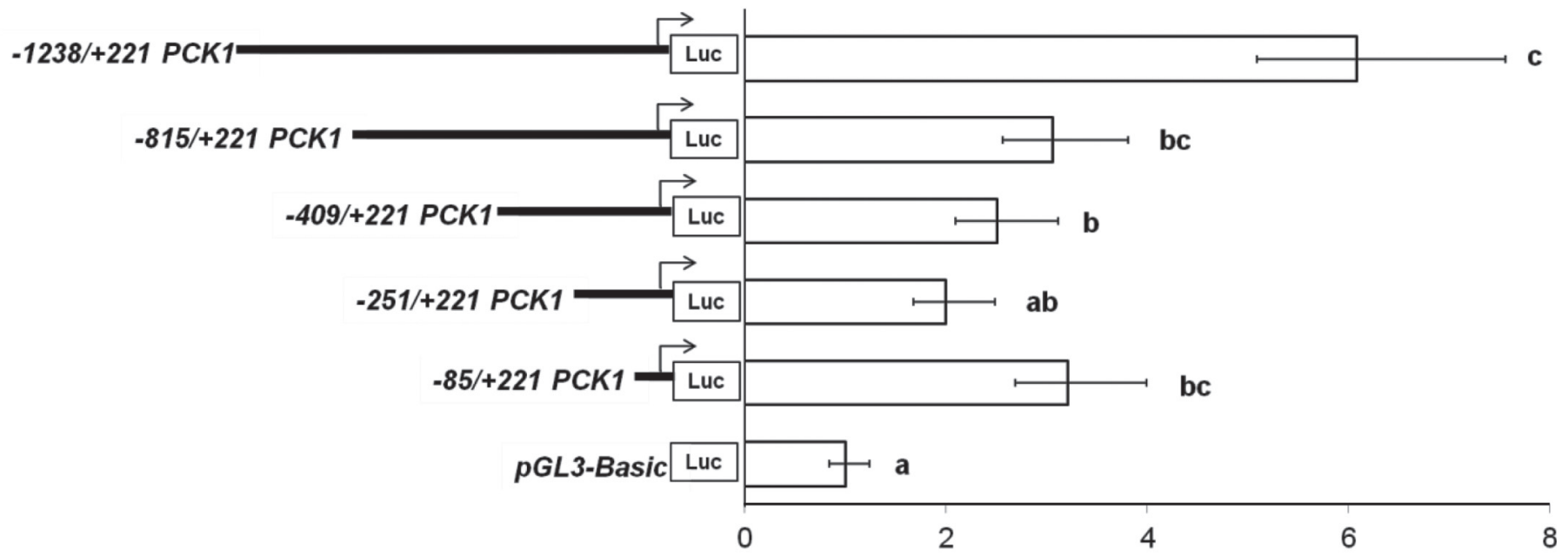

Promoter-Luciferase Reporter Constructs

Promoter Activity, Fold of pGL3-Basic Control

Figure 5. Identification of propionate-responsive regions within the bovine PCK1 promoter. Rat H4IIE cells were transfected with the PCK1 promoter $(-1,238 /+221)$ and its nested $5^{\prime}$ deletions separately and exposed to either 0 or $2.5 \mathrm{~m} M$ of propionate for $23 \mathrm{~h}$. Propionate induction for each promoter reporter is expressed as fold change relative to the no-addition control. Values are LSM and $95 \%$ CI, $\mathrm{n}=3$. Labeled means without a common letter $(\mathrm{a}-\mathrm{c})$ differ at $P<0.05$.

the cell is necessary to enable to capacity for the complete oxidation of acetyl-CoA that is generated from fatty acids through $\beta$-oxidation during negative energy balance in dairy cattle (Baird et al., 1968; Li et al.,
2012). Increased $P C K 1$ activity that is unmatched by change in PCK activity may lead to diminution of OAA (Jitrapakdee et al., 2008). Propionate can replenish the OAA pool through propionyl CoA and methylmalonyl-
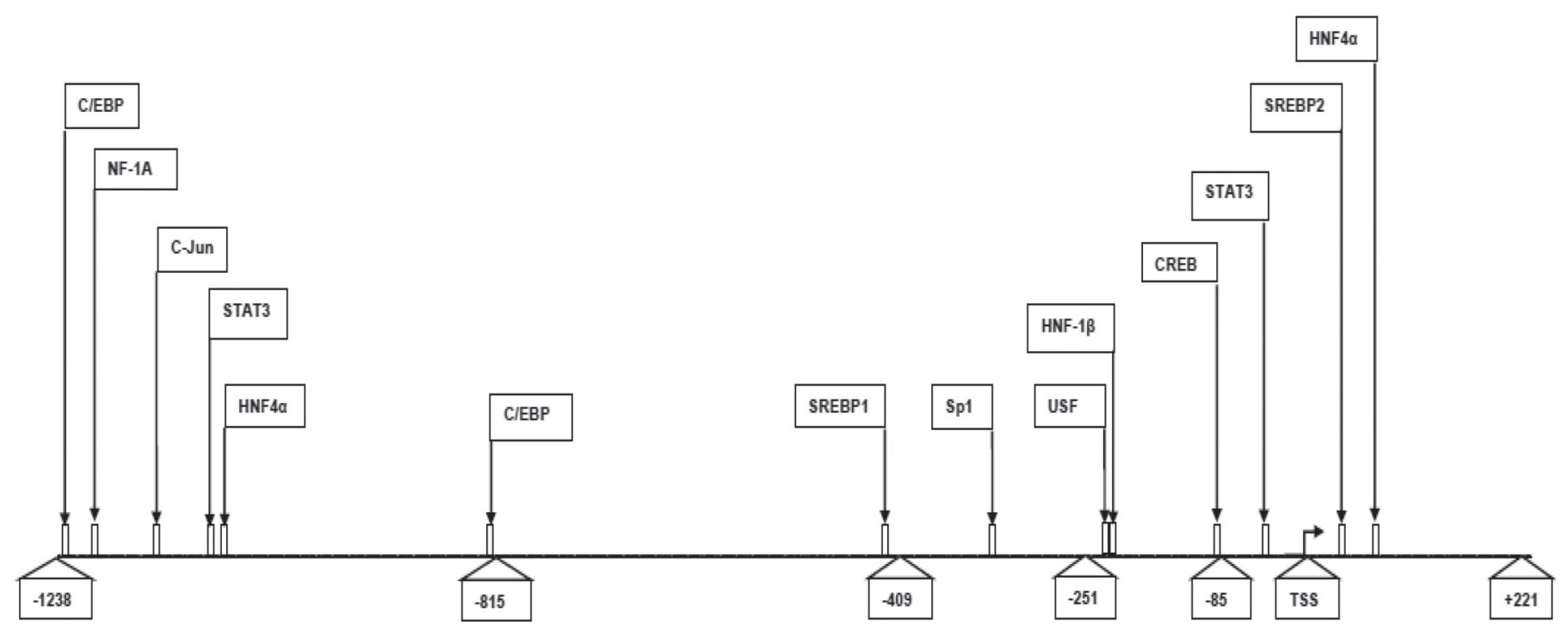

Figure 6. A diagram of the proximal promoter of the bovine PCK1 gene. Transcription start site is indicated as TSS. Putative transcription factor binding sites within the promoter $(-1,238$ through +221$)$ was identified using the TRANSFAC transcription factor analysis tool (Biobase, Beverly, MA). The search parameters were limited to liver-specific factors, high-quality matrices, and were set to minimize the number of false positives. Abbreviations for common transcription factors: $\mathrm{C} / \mathrm{EBP}=\mathrm{CCAAT} /$ enhancer binding protein, NF-1A $=$ nuclear factor $1 \mathrm{~A}$, STAT3 $=$ signal transducer and activator of transcription $3, \mathrm{HNF} 4 \alpha=$ hepatic nuclear factor $4 \alpha, \mathrm{SREBP}=$ sterol regulatory element-binding protein, $\mathrm{Sp} 1=$ specificity protein $1, \mathrm{USF}=$ upstream stimulatory factor, HNF-1 $\beta=$ hepatic nuclear factor $1 \beta, \mathrm{CREB}=$ cyclic AMP response element binding protein. 
CoA metabolism (Aschenbach et al., 2010). In contrast, butyrate cannot be converted to OAA. The present data indicate butyrate is a potent inducer of bovine PCK1 transcription and exhibits roughly double the effect of a similar concentration of propionate. Because butyrate carbon does not enter the OAA pool, the potential exists to reduce the oxidative capacity of the tricarboxylic acid cycle by increased PCK1 activity that is not matched by metabolism that replenishes OAA. Induction of $P C K 1$ by butyrate without a matched increase in propionate supply may lead to a pattern of metabolism marked by a reduction of OAA pool, and therefore compromised capacity for acetyl-CoA oxidation. A resulting buildup of the intracellular acetyl CoA may potentiate hepatic ketogenesis in an attempt to shuttle energy to peripheral tissues. Increased butyrate to propionate ratio in the rumen by dietary supplementation of $\alpha$-amylase is reported to be accompanied with elevated blood concentrations of $\mathrm{BHB}$, one of the ketone bodies in dairy cattle (DeFrain et al., 2005; Tricarico et al., 2005, 2008). Increased ketogenesis in response to increased ruminal supply of butyrate (Huhtanen et al., 1993) supports a role of butyrate in altering hepatic energy metabolism. Our data have suggested an underlying mechanism for these observations. The regulation of bovine PCK1 transcription and effect of propionate and butyrate proportions in conjunction with effects on cellular capacity for gluconeogenesis and fatty acid oxidation were not investigated in the present study and warrant further investigation.

In addition to regulation by propionate and butyrate, the bovine $P C K 1$ promoter activity was also regulated by cAMP, dexamethasone, and insulin. The pattern of regulation by these hormones in bovine is similar to rat in that $P C K 1$ is stimulated by glucagon (via cAMP) and glucocorticoids and repressed by insulin (Hanson and Patel, 1994; Hanson and Reshef, 1997). These similarities are not surprising because the promoter $(-1,000 \mathrm{bp}$ to the TSS) of the rat and bovine $P C K 1$ gene have several high conserved regions that correspond to several transcription factor binding sites, such as the cAMP response element (Yang et al., 2009), which is involved in the full induction of rat $P C K 1$ promoter by both cAMP (Roesler, 2000) and glucocorticoids (Imai et al., 1990; Scott et al., 1998). A putative cAMP response element was also identified within the bovine PCK1 promoter located at -94 bp (Figure 6 ) and may be the key regulatory element mediating the responsiveness of the bovine $P C K 1$ promoter to cAMP and dexamethasone.

Even though the regulation of $P C K 1$ transcription by cAMP, dexamethasone, insulin, and propionate has been reported in rodents (Hanson and Reshef, 1997; Massillon et al., 2003), to our knowledge this is the first study to investigate the relationship between propionate and these hormonal cues in regulation of $P C K 1$

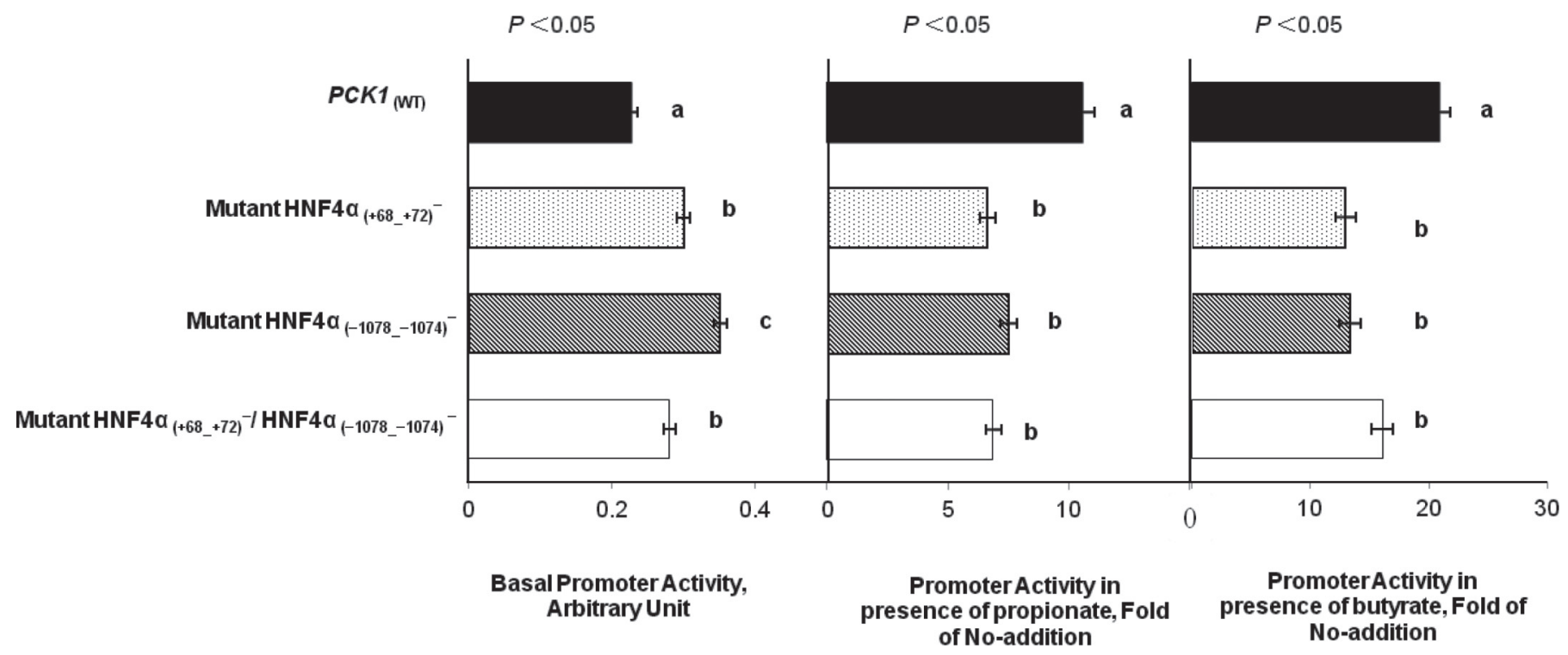

Figure 7. The role of the putative HNF4 $\alpha$ binding sites within the bovine $P C K 1$ promoter in mediating the responsiveness to propionate or butyrate. Rat H4IIE cells were transfected with the $P C K 1_{(\text {WT })}$ and the mutant HNF4 $\alpha_{\left(+68_{-}+72\right)^{-}}$, mutant HNF4 $\alpha_{\left(-1,078_{-}-1,074\right)}{ }^{-}$, and double mutant HNF $4 \alpha_{(+68+72)}{ }^{-} / \mathrm{HNF}_{4} \alpha_{(-1,078-1,074)}{ }^{-}$separately and exposed to either 0 or $2.5 \mathrm{~m} M$ of propionate or $2.5 \mathrm{~m} M$ butyrate for $23 \mathrm{~h}$. Inductions by propionate or butyrate for each promoter reporter are expressed as fold change relative to the no-addition control. Values are LSM \pm SEM, $n$ $=3$. Labeled means without a common letter $(\mathrm{a}-\mathrm{c})$ differ at $P<0.05$. 
transcription in any species. The extent of induction of bovine PCK1 transcription in response to propionate far exceeded the induction by cAMP and dexamethasone, and this effect is not repressed by insulin, indicating propionate is a primary regulator for bovine PCK1 expression. The dominant induction of PCK1 transcription by propionate over the repressive effect of insulin is consistent with the unique characteristic of ruminants that gluconeogenic rate is increased after feeding despite increased insulin concentration in blood (Aschenbach et al., 2010). Additionally, stimulation of $P C K 1$ transcription by hormonal signals, such as cAMP and dexamethasone, is likely to be more important during feed restriction. Otherwise, a decrease in expression of PCK1 mRNA would be an anticipated outcome of reduced propionate supply; but clearly this is not the case in vivo, as PCK1 mRNA in liver is not altered during feed restriction over a 5 -d period in dairy cows (Velez and Donkin, 2005).

\section{CONCLUSIONS}

These data demonstrate hormonal and nutritional regulation of PCK1 transcription in bovine. The promoter activity of bovine PCK1 is induced by cAMP, dexamethasone, propionate, and butyrate. Insulin exhibits a dominant inhibition on the cAMP- and dexamethasone-induced $P C K 1$ transcription, but fails to repress propionate-induced PCK1 transcription. Propionate, as a major gluconeogenic precursor in ruminants, controls its own metabolism in liver via inducing $P C K 1$ transcription.

\section{ACKNOWLEDGMENTS}

This project was supported in part by National Research Initiative Competitive Grant no. 2006-3520616646 from the USDA National Institute of Food and Agriculture (Washington, DC). Qian Zhang and Shawn S. Donkin designed research; Qian Zhang and Stephanie L. Koser conducted research; Qian Zhang analyzed data, and Qian Zhang and Shawn S. Donkin wrote the paper; Shawn S. Donkin had primary responsibility for final content. All authors read and approved the final manuscript.

\section{REFERENCES}

Aschenbach, J. R., N. B. Kristensen, S. S. Donkin, H. M. Hammon, and G. B. Penner. 2010. Gluconeogenesis in dairy cows: the secret of making sweet milk from sour dough. IUBMB Life 62:869-877.

Babeu, J.-P., and F. Boudreau. 2014. Hepatocyte nuclear factor 4-alpha involvement in liver and intestinal inflammatory networks. World J. Gastroenterol. 20:22-30.
Baird, G. D. 1982. Primary ketosis in the high-producing dairy cow: Clinical and subclinical disorders, treatment, prevention, and outlook. J. Dairy Sci. 65:1-10.

Baird, G. D., K. G. Hibbitt, and G. D. Hunter. 1968. Biochemical aspects of bovine ketosis. Biochem. J. 107:683-689.

Brown, A. J., S. M. Goldsworthy, A. A. Barnes, M. M. Eilert, L. Tcheang, D. Daniels, A. I. Muir, M. J. Wigglesworth, I. Kinghorn, and N. J. Fraser. 2003. The Orphan G protein-coupled receptors GPR41 and GPR43 are activated by propionate and other short chain carboxylic acids. J. Biol. Chem. 278:11312-11319.

Burgess, S. C., T. T. He, Z. Yan, J. Lindner, A. D. Sherry, C. R. Malloy, J. D. Browning, and M. A. Magnuson. 2007. Cytosolic phosphoenolpyruvate carboxykinase does not solely control the rate of hepatic gluconeogenesis in the intact mouse liver. Cell Metab. $5: 313-320$.

Chakravarty, K., H. Cassuto, L. Reshef, and R. W. Hanson. 2005. Factors that control the tissue-specific transcription of the gene for phosphoenolpyruvate carboxykinase-C. Crit. Rev. Biochem. Mol. Biol. 40:129-154.

Chakravarty, K., and R. W. Hanson. 2007. Insulin regulation of phosphoenolpyruvate carboxykinase-C gene transcription: The role of sterol regulatory element-binding protein 1c. Nutr. Rev. 65:S47S56.

DeFrain, J. M., A. R. Hippen, K. F. Kalscheur, and J. M. Tricarico. 2005. Effects of dietary $\alpha$-amylase on metabolism and performance of transition dairy cows. J. Dairy Sci. 88:4405-4413.

Duffield, T. F., D. Sandals, K. E. Leslie, K. Lissemore, B. W. McBride, J. H. Lumsden, P. Dick, and R. Bagg. 1998. Efficacy of monensin for the prevention of subclinical ketosis in lactating dairy cows. J. Dairy Sci. 81:2866-2873.

Gonzalez, F. J. 2008. Regulation of hepatocyte nuclear factor 4 alphamediated transcription. Drug Metab. Pharmacokinet. 23:2-7.

Granner, D., T. Andreone, K. Sasaki, and E. Beale. 1983. Inhibition of transcription of the phosphoenolpyruvate carboxykinase gene by insulin. Nature 305:549-551.

Greenfield, R. B., M. J. Cecava, and S. S. Donkin. 2000. Changes in mRNA expression for gluconeogenic enzymes in liver of dairy cattle during the transition to lactation. J. Dairy Sci. 83:1228-1236.

Hanson, R. W., and Y. M. Patel. 1994. Phosphoenolpyruvate carboxykinase (GTP): The gene and the enzyme. Adv. Enzymol. Relat. Areas Mol. Biol. 69:203-281.

Hanson, R. W., and L. Reshef. 1997. Regulation of phosphoenolpyruvate carboxykinase (GTP) gene expression. Annu. Rev. Biochem. 66:581-611.

Huhtanen, P., H. Miettinen, and M. Ylinen. 1993. Effect of increasing ruminal butyrate on milk yield and blood constituents in dairy cows fed a grass silage-based diet. J. Dairy Sci. 76:1114-1124.

Imai, E., P. E. Stromstedt, P. G. Quinn, J. Carlstedt-Duke, J. A. Gustafsson, and D. K. Granner. 1990. Characterization of a complex glucocorticoid response unit in the phosphoenolpyruvate carboxykinase gene. Mol. Cell. Biol. 10:4712-4719.

Jitrapakdee, S., M. St Maurice, I. Rayment, W. Cleland, J. Wallace, and P. Attwood. 2008. Structure, mechanism and regulation of pyruvate carboxylase. Biochem. J. 413:369-387.

Karcher, E. L., M. M. Pickett, G. A. Varga, and S. S. Donkin. 2007. Effect of dietary carbohydrate and monensin on expression of gluconeogenic enzymes in liver of transition dairy cows. J. Anim. Sci. 85:690-699.

Layden, B. T., A. R. Angueira, M. Brodsky, V. Durai, and W. L. Lowe Jr.. 2013. Short chain fatty acids and their receptors: New metabolic targets. Transl. Res. 161:131-140.

Li, P., X. B. Li, S. X. Fu, C. C. Wu, X. X. Wang, G. J. Yu, M. Long, Z. Wang, and G. W. Liu. 2012. Alterations of fatty acid $\beta$-oxidation capability in the liver of ketotic cows. J. Dairy Sci. 95:1759-1766.

Massillon, D., I. J. Arinze, C. Xu, and F. Bone. 2003. Regulation of glucose-6-phosphatase gene expression in cultured hepatocytes and H4IIE cells by short-chain fatty acids: Role of hepatic nuclear

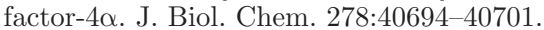

Puigserver, P. 2005. Tissue-specific regulation of metabolic pathways through the transcriptional coactivator PGC1- $\alpha$. Int. J. Obes. (Lond.) 29:S5-S9. 
Ramadoss, P., N. E. Unger-Smith, F. S. Lam, and A. N. Hollenberg. 2009. STAT3 targets the regulatory regions of gluconeogenic genes in vivo. Mol. Endocrinol. 23:827-837.

Rhee, J., Y. Inoue, J. C. Yoon, P. Puigserver, M. Fan, F. J. Gonzalez, and B. M. Spiegelman. 2003. Regulation of hepatic fasting response by PPAR $\gamma$ coactivator- $1 \alpha$ (PGC-1): requirement for hepatocyte nuclear factor $4 \alpha$ in gluconeogenesis. Proc. Natl. Acad. Sci. USA 100:4012-4017.

Roesler, W. J. 2000. What is a cAMP response unit? Mol. Cell. Endocrinol. 162:1-7.

Rognstad, R. 1979. Rate-limiting steps in metabolic pathways. J. Biol. Chem. 254:1875-1878.

Scott, D. K., P. E. Stromstedt, J. C. Wang, and D. K. Granner. 1998 Further characterization of the glucorticoid response unit in the PEPCK gene. The role of the glucocorticoid receptor binding sites. Mol. Endocrinol. 12:482-491.

She, P., M. Shiota, K. D. Shelton, R. Chalkley, C. Postic, and M. A. Magnuson. 2000. Phosphoenolpyruvate carboxykinase is necessary for the integration of hepatic energy metabolism. Mol. Cell. Biol. 20:6508-6517.

Sladek, F. M., W. M. Zhong, E. Lai, and J. E. Darnell. 1990. Liver-enriched transcription factor HNF-4 is a novel member of the steroid hormone receptor superfamily. Genes Dev. 4:2353-2365.

Tang, X. L., Y. Wang, D.-L. Li, J. Luo, and M.-Y. Liu. 2012. Orphan $\mathrm{G}$ protein-coupled receptors (GPCRs): Biological functions and potential drug targets. Acta Pharmacol. Sin. 33:363-371.
Tricarico, J. M., J. D. Johnston, and K. A. Dawson. 2008. Dietary supplementation of ruminant diets with an Aspergillus oryzae $\alpha$-amylase. Anim. Feed Sci. Technol. 145:136-150.

Tricarico, J. M., J. D. Johnston, K. A. Dawson, K. C. Hanson, K. R. McLeod, and D. L. Harmon. 2005. The effects of an Aspergillus oryzae extract containing alpha-amylase activity on ruminal fermentation and milk production in lactating Holstein cows. Anim. Sci. 81:365-374

Velez, J. C., and S. S. Donkin. 2005. Feed restriction induces pyruvate carboxylase but not phosphoenolpyruvate carboxykinase in dairy cows. J. Dairy Sci. 88:2938-2948.

Wang, A., Z. Gu, B. Heid, R. M. Akers, and H. Jiang. 2009. Identification and characterization of the bovine $\mathrm{G}$ protein-coupled receptor GPR41 and GPR43 genes. J. Dairy Sci. 92:2696-2705.

Yang, J., L. Reshef, H. Cassuto, G. Aleman, and R. W. Hanson. 2009 Aspects of the control of phosphoenolpyruvate carboxykinase gene transcription. J. Biol. Chem. 284:27031-27035.

Yonezawa, T., S. Haga, Y. Kobayashi, K. Katoh, and Y. Obara. 2009 Short-chain fatty acid signaling pathways in bovine mammary epithelial cells. Regul. Pept. 153:30-36.

Zhang, Q., S. L. Koser, B. J. Bequette, and S. S. Donkin. 2015. Effect of propionate on mRNA expression of key genes for gluconeogenesis in liver of dairy cattle. J. Dairy Sci. 98:8698-8709. 